\title{
A Note on Terminology
}

One of the most frequently used concepts in this book is "culture." Among contemporary theorists, the concept is understood in two distinct ways. One tradition, associated perhaps most famously with Raymond Williams, takes it to mean an entire "way of life" - the gamut of social practices that distinguish one social formation or one epoch from another. This includes not only religion, ideology, the arts, and literature but also political and economic institutions. Another, more narrow use of the term uses it to denote ideology, discourse, normative codes, and so ontogether comprising the interpretive dimension of social practices. In this book, unless otherwise noted, I will always use "culture" and its cognates in the latter sense. There is a reason for this. One of the primary goals of the book is to respond to the challenges to structural class theory issued by proponents of the "cultural turn." That challenge only makes sense if "culture" is understood in this particular way-as will be clear in the course of the book. It is a practical decision, not an epistemological stance. Readers who feel strongly that the concept should not be used in this fashion can feel free to substitute "ideology" or "discourse" whenever they see "culture." I usually use them interchangeably. 

The Class Matrix 
